\title{
Hydroxyapatite- and Amelogenin Protein-Induced Expression of Mineralization-Related Genes in a Dental Epithelial Cell Line
}

\author{
Liming $\mathrm{Xu}^{1, *}$, Hidemitsu Harada ${ }^{2}$, Toshiyuki Ikoma ${ }^{3}$ and Akiyoshi Taniguchi ${ }^{1}$
}

${ }^{I}$ Cell-Sensing Group and ${ }^{3}$ Biosystem and Biomolecule Control Group, Biomaterials Center, National Institute for Materials Science, 1-1 Namiki, Tsukuba, Ibaraki 305-0044, Japan and ${ }^{2}$ Department of Oral Anatomy II, Iwate Medical University, School of Dentistry, 1-3-27 Chuodori, Morioka, Iwate 020-8505, Japan

\begin{abstract}
Hydroxyapatite (HAp), a major inorganic component of hard tissues, has been widely used as a novel scaffold for bone or tooth tissue regeneration. However, the effects of HAp on dental cells at the molecular level are poorly understood. In the present study, we evaluated the effects of HAp on differentiation- and mineralization-related gene expression in the dental epithelial cell line (HAT-7). HAT-7 cells were observed to spread on the surface of HAp sintered disks and to increase the expression of several differentiation- and mineralization-related genes. Furthermore, amelogenin and HAp synergistically induced differentiation resulting in increased amelogenin mRNA expression in HAT-7 cells. The results from this study provide important information to develop novel biomaterials for enamel regeneration.
\end{abstract}

\section{INTRODUCTION}

Amelogenin is a major component of enamel matrix proteins, accounting for more than $90 \%$ of enamel matrix proteins [1]. We have previously reported that amelogenins induce differentiation of the dental epithelial cell line (HAT-7) and in an autocrine manner increase levels of amelogenin mRNA by enhancing its stability $[2,3]$. Through this unique auto-regulatory mechanism amelogenins are produced in large quantities by ameloblasts and accelerate enamel formation. Ameloblastin, is another enamel matrix protein that comprises $5-10 \%$ of enamel matrix proteins [1]. It is a cell adhesion molecule that plays a role in maintaining the differentiation state of secretory ameloblasts [4].

Enamel formation is a unique matrix protein-mediated biomineralization process. In the early stage the enamel matrix primarily comprises enamel matrix proteins, but the composition shifts from enamel matrix proteins to hydroxyapatite (HAp), the major non-organic component of the enamel matrix, and by the maturation stage is finally entirely replaced by HAp. HAp, as a major inorganic component of hard tissues, has been widely used as a novel scaffold for mineral-related tissue engineering [5-9] and as carrier for delivery of some growth factors [10-15]. HAp-coated dental implants had been investigated clinically [16-23]. The data suggest that HAp-coated implants may be able to maintain optimal osseointegration over time, though the molecular mechanisms by which HAp affects dental cell differentiation and mineralization are poorly understood [23].

In present study, we evaluated the effects of HAp sintered disks on expression of cell differentiation- and mineralization-related genes in a dental epithelial cell line, and also evaluated the combined effects of amelogenin and HAp on differentiation. The data from this study will provide important information for tooth regeneration.

*Address correspondence to this author at the Cell-Sensing, Biomaterials Center, National Institute for Materials Science, 1-1 Namiki, Tsukuba, Ibaraki 305-0044, Japan; E-mail: XU.Liming@nims.go.jp

\section{MATERIALS AND METHODS}

\section{Preparation of HAp Sintered Disk}

Single phase HAp powder was prepared by wet method from $\mathrm{Ca}(\mathrm{OH})_{2}$ suspension adjusted to a $\mathrm{pH} 8$ with $\mathrm{H}_{3} \mathrm{PO}_{4}$ solution [24]. Spherical particles were obtained with a spraydryer and were calcined at $800^{\circ} \mathrm{C}$ for $1-3 \mathrm{~h}$. Polyvinyl alcohol and triethylene glycol were then incorporated as binders. The green bodies were fabricated under a uniaxial pressure of $30 \mathrm{MPa}$ and were then sintered in air at $1200^{\circ} \mathrm{C}$ for $3 \mathrm{~h}$. HAp disks were polished with diamond abrasives (particle size, $3 \mu \mathrm{m}$ ) to reduce the surface roughness and to obtain a mirrored surface. The polished disks were washed three times in distilled water in an ultrasound bath and were then annealed at $800^{\circ} \mathrm{C}$ for $1 \mathrm{~h}$. The surface of the HAp sintered disks was imaged by scanning electron microscopy (SEM).

\section{Cell Culture}

HAT-7 cells, a dental epithelial cell line originating from apical bud of a rat incisor [25] were cultured in Dulbecco's Modified Eagle's Medium (DMEM)/F-12 (GIBCO BRL, USA) supplemented with $10 \%$ fetal bovine serum and penicillin $(100 \mathrm{units} / \mathrm{ml}) /$ streptomycin $(100 \mu \mathrm{g} / \mathrm{ml})$. All cultures were maintained in humidified atmosphere of $5 \% \mathrm{CO}_{2}$ at $37^{\circ} \mathrm{C}$.

\section{Sample Preparation for Observation of Cell Morphology by Atomic Force Microscopy}

Cells cultured on the surface of a HAp sintered disk were washed two times with PBS. Then the samples were fixed with $2.5 \%$ glutaraldehyde in PBS solution for $30 \mathrm{~min}$, and then dehydrated in graded alcohol baths $(50 \%, 70 \%, 90 \%$ and $100 \%$ ) for $15 \mathrm{~min}$, respectively. Samples were vacuum dried overnight then observed under an atomic force microsope (AFM) (Digital Instruments, Dimention 3100). The image was generated by simultaneous acquisition of height and phase signals. 


\section{RNA Extraction and Real-Time RT-PCR}

The mRNA expression of differentiation- and mineralization-related marker genes was determined by quantitative real-time RT-PCR using SYBR green, as previously described [2]. Briefly, total RNA was extracted at various time points with ISOGEN (Nippon Gene, Japan). Total RNA (4 $\mu \mathrm{g})$ was reverse transcribed into cDNA with Super Script First-Strand Synthesis System (Invitrogen, USA) according to the manufacturer's protocol. Expression data was normalized to the housekeeping gene, glyceraldehyde-3-phosphate dehydrogenase (GAPDH) as an endogenous control. The primers for real-time RT-PCR were designed with PrimerExpress software (Applied Biosystems, USA) and are provided in Table $\mathbf{1}$.

Table 1. Real-time PCR Primers

\begin{tabular}{lll}
\hline amelogenin & $\begin{array}{l}\text { Forward } \\
\text { Reverse }\end{array}$ & 5'-TGGGAGCCCTGGTTATATCAA-3' \\
& 5CTGCCTTATCATGCTCTGGTA-3' \\
\hline ameloblastin & Forward & 5'-TTCACCCAAGGGAGGAGACTT-3' \\
& Reverse & 5'-CTCTCCTTTCTCAGGGCCTTTAGT-3' \\
\hline Osteopontin & Forward & 5'-GTTTTGGGCCCTGAGCTTAGTT-3' \\
& Reverse & 5'-AGAAGCGAAATGCTGAAACTTCTAG-3' \\
\hline BSP & Forward & 5'-AACTCAGAGGATCCGGAAACAC-3' \\
& Reverse & 5'-GATGATTCTGCCCTCCGTAGTC-3' \\
\hline \multirow{2}{*}{ BMP-2 } & Forward & 5'-CCGTGCTCAGCTTCCATCA-3' \\
& Reverse & 5'-GGGAAGTTTTCCACTCATT TCT-3' \\
\hline ALP & Forward & 5'-GCAGGATCGGAACGTCAATTA-3' \\
& Reverse & 5'-CTCGCTGGAGCCCAGATG-3' \\
\hline GAPDH & Forward & 5'-GCCCCCAACACTGAGCAT-3' \\
& Reverse & 5'-CCAGGCCCCTCCTGTTGT-3' \\
\hline
\end{tabular}

\section{Statistical Analysis}

Data are presented as means \pm SD. Single group comparisons were evaluated with the Student's t-test method. Statistical significance was set at $* \mathrm{P}<0.01, * * \mathrm{P}<0.001$.

\section{RESULTS}

\section{Structure of HAp Sintered Disk Surface and Morphology of the HAT-7 Cell Cultured on the HAp Surface}

To evaluate the effects of hydroxyapatite sintered disk on expression of cell differentiation- and mineralization-related genes in a dental epithelial cell line, we first visualized the surface structure of the HAp sintered disk by SEM. The SEM revealed various size hydroxyapatite crystals and smooth roughness in the surface of the disk (Fig. 1, left panel). HAT-7 cells cultured on the surface of a HAp sintered disk were spread taut (Fig. 1, right panel). The attachment of the cells cultured on the surface of HAp sintered disk did not differ from that of cells cultured on the tissue culture polystyrene (TCP) plate (data not shown).

\section{Effects of HAp on HAT-7 Cell Gene Expression}

To investigate the effects of HAp on gene expression in dental epithelial cells, HAT-7 cells were cultured on the surface of a HAp sintered disk and the mRNA expression levels of various genes were determined. Amelogenin mRNA ex- pression was found to be slightly increased at day 3 and day 7. Ameloblastin, osteopontin, bone sialoprotein, bone morphogenetic protein-2 and alkaline phosphatase mRNA expression increased significantly when the cells were cultured on the surface of a HAp sintered disk compared with that of cells cultured on a TCP plate (Fig. 2). Up-regulation of these mRNAs was observed at day 1 and increased expression levels were maintained for the two-week experimental period (Fig. 2). These results suggested that HAp contributes to dental epithelial cell differentiation and mineralization.
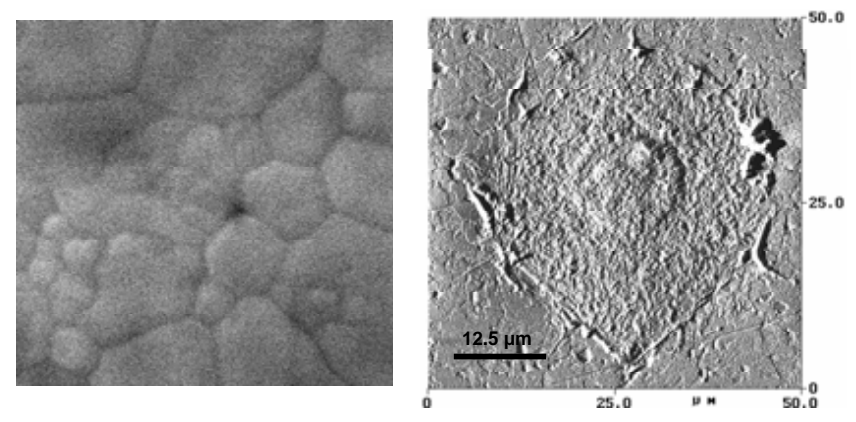

Fig. (1). SEM image of the surface of HAp sintered disk (Left panel), and AFM image of HAT-7 cell cultured on this surface (Right panel). The preparation of HAp sintered disks is described in Materials and Methods.

\section{Amelogenin Protein and HAp Synergistically Increase Amelogenin mRNA Expression}

We have previously demonstrated that amelogenin protein induces HAT-7 cell differentiation and in an autocrine fashion results in an increase of amelogenin mRNA expression [2]. To determine whether amelogenin protein and HAp cooperate in inducing dental epithelial cell differentiation and mineralization, HAT-7 cells were cultured on a HAp sintered disk and in the presence of exogenous amelogenin proteins. Endogenous amelogenin mRNA expression was significantly and synergistically increased when the cells were cultured on HAp in the presence of amelogenin proteins (Fig. 3). The synergistic effects of HAp and amelogenin protein application were not observed in the expression of mineralization-related genes such as ameloblastin and osteopontin (data not shown). These results suggested that amelogenin protein and HAp cooperate to induce differentiation of dental epithelial cells resulting in increased amelogenin mRNA expression.

Tooth tissue engineering, like other tissues, requires integration of three key elements: the responding progenitor/stem cells, growth factors, and the extracellular matrix scaffold. In a previous study, we demonstrated that BMP-2 induced dental epithelial cell differentiation resulting in increased amelogenin and ameloblastin mRNA expression in vitro [26], suggesting that the BMPs have important role in the controlling differentiation of dental epithelial cells. We also previously reported that the enamel matrix protein amelogenin induced differentiation of the dental epithelial cell line (HAT-7) resulting in increased levels of amelogenin mRNA through enhancing mRNA stabilization in an autocrine manner $[2,3]$. The current study, reveals that the primary inorganic component of enamel matrix, HAp, in- 
creases differentiation of HAT-7 cells and induces expression of mineralization-related genes (Fig. 2), suggesting that HAp plays a role in dental epithelial cell differentiation and

A

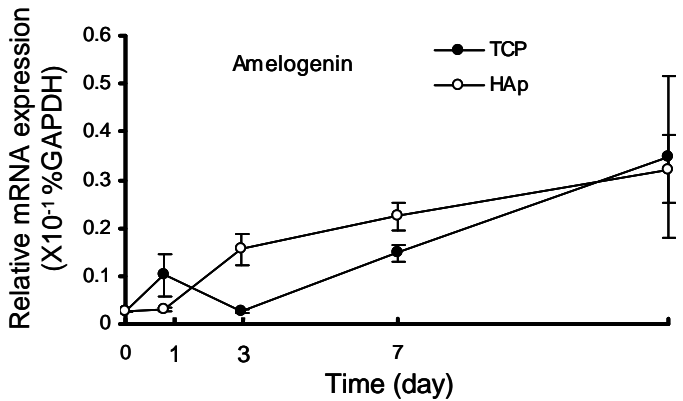

B

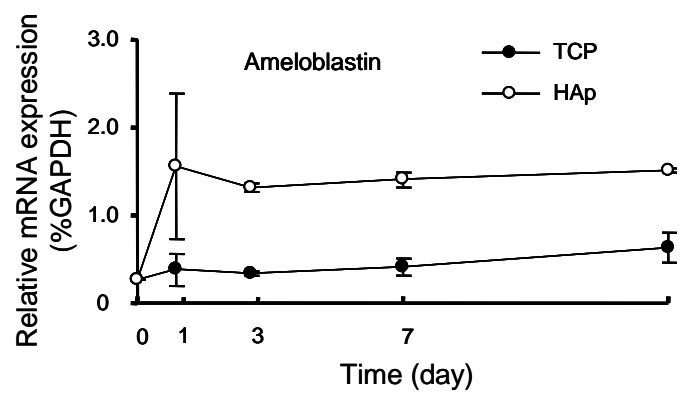

C

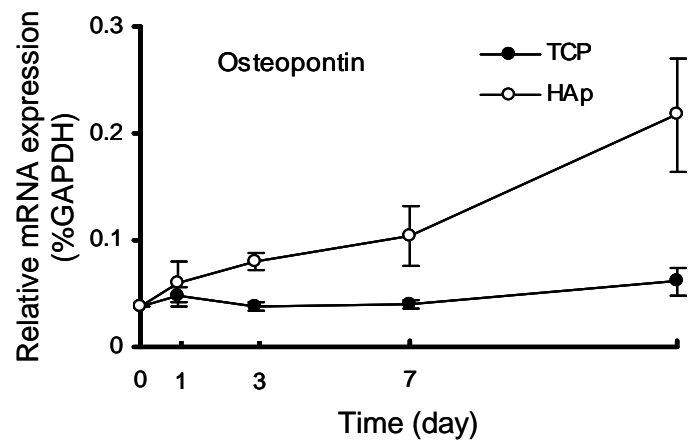

D
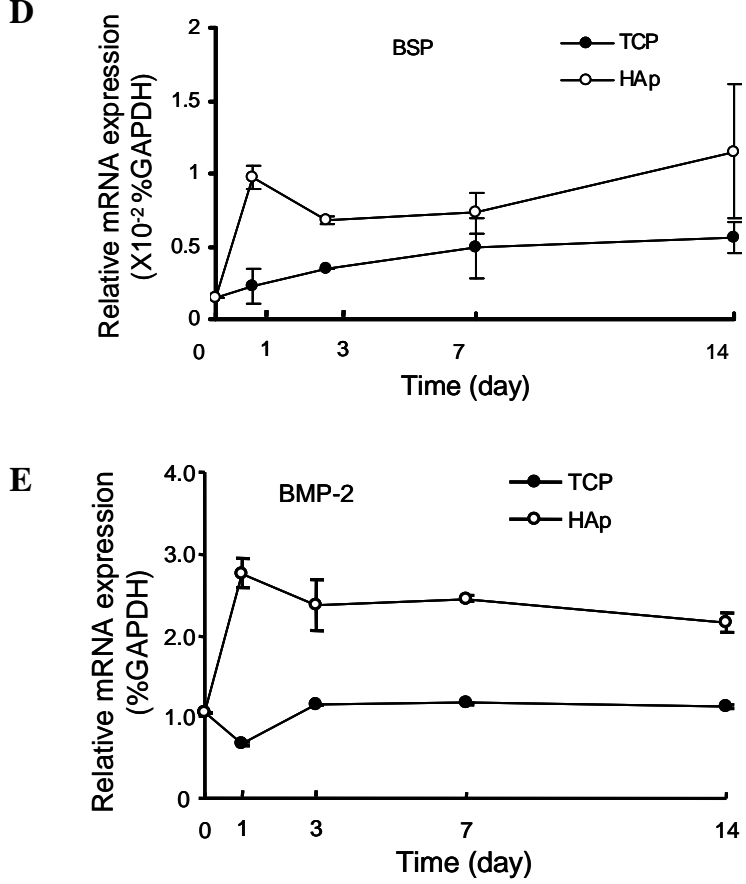

F

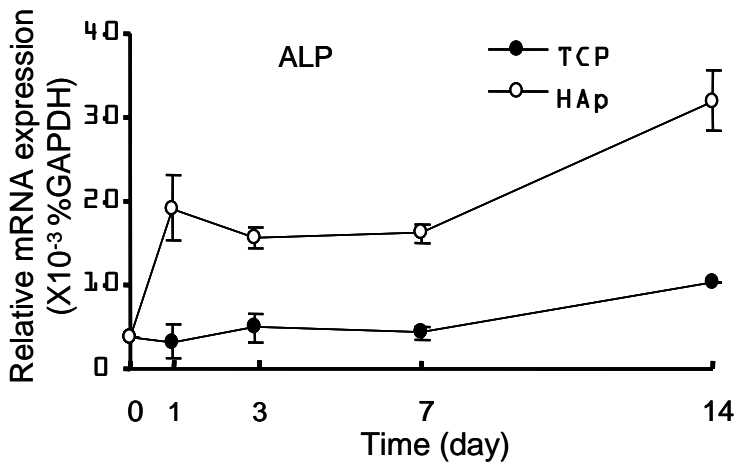

Fig. (2). mRNA expression of HAT-7 cells cultured on the surface of HAp sintered disk. A: Amelogenin; B: Ameloblastin; C: Osteopontin; D: Bone sialoprotein (BSP); E: Bone morphogenetic protein-2 (BMP-2); F: Alkaline phosphatase (ALP). HAT-7 cells were seeded on the surface of a HAp sintered disk with $600 \mu$ l culture medium containing $2.5 \times 10^{5}$ cells. After the cells attached, medium was adjusted to $1 \mathrm{ml}$ and cells were cultured for $0,1,3,7,14$ days. Media were changed at every two days. mRNA expression was determined by real-time RT-PCR. The results are representative of three separated experiments. Error bars indicate mean \pm SD. The cells cultured in tissue culture polystyrene plate (TCP) were served as control.

mineralization. Furthermore, we find that amelogenin proteins and HAp cooperate to induce differentiation of dental epithelial cells resulting in even further induction of amelogenin mRNA expression, suggesting that cell-matrix interactions are important in enamel formation.

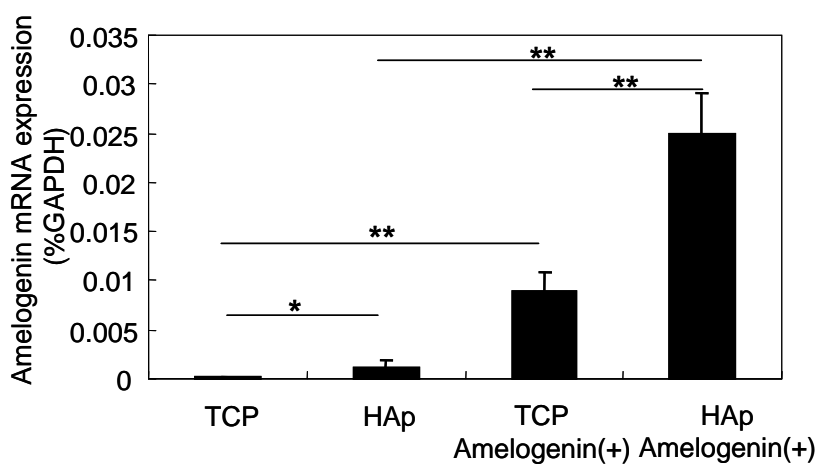

Fig. (3). Amelogenin mRNA expression. HAT-7 cells were cultured on tissue culture polystyrene plate (TCP) or the surface of a HAp sintered disk (HAp), in the presence or absence of amelogenin protein for 3 days. The results are representative of three separated experiments. Error bars indicate mean \pm SD. *, p $<0.01 ; * *, p<0.001$.

\section{DISCUSSION}

The mechanisms involved in biological effects of HAp on the cells have been previously discussed [27, 28]. Calcium is a key component of the mineralized enamel matrix. The morphology of human ameloblast lineage cells is altered by increased calcium in the media, and differentiating ameloblast-lineage cells can be maintained in a functional state by culturing in the presence of $0.05 \mathrm{mM}$ calcium [29, 30]. The calcium sensing receptor in enamel organ epithelialderived cells has been identified [31, 32]. These observations suggested a signal role for calcium in ameloblast lineage cell differentiation and mineralization. In the case of present 
study, when dental epithelial cells (HAT-7) were cultured on the surface of a HAp sintered disk, calcium released from the HAp sintered disk would able to promote HAT-7 cell differentiation and mineralization resulting in upregulation of differentiation and mineralization-related genes expression.

The excellent adsorptive capability and biocompatibility of HAp are believed to help adsorb activation factors from the medium, thereby inducing cell attachment, proliferation and/or differentiation. The data from in vitro organ culture suggests that BMP-2-soaked apatite induces functional differentiation of ameloblasts resulting in amelogenin secretion [33]. We have previously demonstrated that amelogenin protein was retaken up by the HAT-7 cells resulting in increased endogenous amelogenin mRNA expression through enhancing mRNA stabilization in the cytoplasm [2]. In the case of HAp and amelogenin protein co-application, HAp may adsorb exogenous amelogenin from the media facilitating the reuptake of amelogenin into the cytoplasm. In this way, HAp and amelogenin protein synergistically increase amelogenin mRNA expression.

In conclusion, we evaluated the biological effects of HAp on dental epithelial cells at the molecular level. The data from this study showed that HAp induced dental epithelial cell differentiation and mineralization through inducing expression of some genes. We proposed that amelogenin protein and HAp cooperate to induce differentiation of dental epithelial cells resulting in increased amelogenin mRNA expression. These results provide important information to develop novel biomaterials for enamel regeneration.

\section{ACKNOWLEDGEMENTS}

We thank Dr. Hong Song Fan (Sichuan University, China) for valuable discussions on HAp materials and technical assistance in atomic force microscopy. This research was supported in part by a grant program "Collaborative Development of Innovative Seeds" from the Japan Science and Technology Agency.

\section{REFERENCES}

[1] Termine JD, Belcourt AB, Christner PJ, et al. Properties of dissociatively extracted fetal tooth matrix proteins. I. Principal molecular species in developing bovine enamel. J Biol Chem 1980; 255: 9760-8.

[2] Xu L, Harada H, Tamaki YT, et al. Reuptake of extracellular amelogenin by dental epithelial cells results in increased levels of amelogenin mRNA through enhanced mRNA stabilization. J Biol Chem 2006; 281: 2257-62.

[3] Xu L, Harada $\mathrm{H}$, Taniguchi A. The exon $6 \mathrm{ABC}$ region of amelogenin mRNA contribute to increased levels of amelogenin mRNA through amelogenin protein-enhanced mRNA stabilization. J Biol Chem 2006; 281: 32439-44.

[4] Fukumoto S, Yamada A, Nonaka K, et al. Essential roles of ameloblastin in maintaining ameloblast differentiation and enamel formation. Cells Tissues Organs 2005; 181: 189-95.

[5] Dellinger JG, Wojtowicz AM, Jamison RD. Effects of degradation and porosity on the load bearing properties of model hydroxyapatite bone scaffolds. J Biomed Mater Res A 2006; 77(3): 563-71.

[6] Tamai M, Isama K, Nakaoka R, et al. Synthesis of a novel betatricalcium phosphate/hydroxyapatite biphasic calcium phosphate containing niobium ions and evaluation of its osteogenic properties. J Artif Organs 2007; 10(1): 22-8.

[7] Wahl DA, Sachlos E, Liu C, et al. Controlling the processing of collagen-hydroxyapatite scaffolds for bone tissue engineering. $\mathbf{J}$ Mater Sci Mater Med 2007; 18(2): 201-9.
[8] Dellinger JG, Cesarano J, Jamison RD. Robotic deposition of model hydroxyapatite scaffolds with multiple architectures and multiscale porosity for bone tissue engineering. J Biomed Mater Res A 2007; 82(2): 383-94.

[9] Rodriguez-Lorenzo LM, Vallet-Regi M, Ferreira JM, et al. Hydroxyapatite ceramic bodies with tailored mechanical properties for different applications. J Biomed Mater Res 2002; 60(1): 159-66.

[10] Laurencin CT, Attawia MA, Lu LQ, et al. Poly(Lactide-coglycolide)/hydroxyapatite delivery of BMP-2-producing cells: a regional gene therapy approach to bone regeneration. Biomaterials 2001; 22(11): 1271-7.

[11] Nie H, Wang CH. Fabrication and characterization of PLGA/HAp composite scaffolds for delivery of BMP-2 plasmid DNA. J Control Release 2007; 120(1-2): 111-21.

[12] Kim HW, Knowles JC, Kim HE. Hydroxyapatite porous scaffold engineered with biological polymer hybrid coating for antibiotic vancomycin release. J Mater Sci Mater Med 2005; 16(3): 189-95.

[13] Letic-Gavrilovic A, Piattelli A, Abe K. Nerve growth factor beta(NGF beta) delivery via a collagen/hydroxyapatite (Col/HAp) composite and its effects on new bone ingrowth. J Mater Sci Mater Med 2003; 14(2): 95-102.

[14] Kaito T, Myoui A, Takaoka K, et al. Potentiation of the activity of bone morphogenetic protein-2 in bone regeneration by a PLA PEG/hydroxyapatite composite. Biomaterials 2005; 26(1): 73-9.

[15] Paul W, Sharma CP. Ceramic drug delivery: a perspective. J Biomater Appl 2003; 17(4): 235-64.

[16] Iezzi G, Scarano A, Petrone G, et al. Two human hydroxyapatitecoated dental implants retrieved after a 14-year loading period: a histologic and histomorphometric case report. J Periodontol 2007; 78(5): 940-7.

[17] Simunek A, Kopecka D, Cierny M, et al. A six-year study of hydroxyapatite-coated root-form dental implants. West Indian Med J 2005; 54(6): 393-7.

[18] Trisi P, Keith DJ, Rocco S. Human histologic and histomorphometric analyses of hydroxyapatite-coated implants after 10 years of function: a case report. Int J Oral Maxillofac Implants 2005; 20(1): 124-30.

[19] Uehara T, Takaoka K, Ito K. Histological evidence of osseointegration in human retrieved fractured hydroxyapatite-coated screw-type implants: a case report. Clin Oral Implants Res 2004; 15(5): 540-5.

[20] Davis DM, Watson RM, Packer ME. Single tooth crowns supported on hydroxyapatite coated endosseous dental implants: a prospective 5-year study on twenty subjects. Int Dent J 2004; 54(4): 201-5.

[21] Froum S, Cho SC, Elian N, et al. Extraction sockets and implantation of hydroxyapatites with membrane barriers: a histologic study. Impalnt Dent 2004; 13(2): 153-64.

[22] Proussaefs P, Lozada J. Immediate loading of hydroxyapatitecoated implants in the maxillary premolar area: three-year results of a pilot study. J Prosthet Dent 2004; 91(3): 228-33.

[23] Stellino G, Landi L. A 6-year unloaded hydroxyapatite-coated dental implant placed into an extraction socket in conjunction with nonresorbable hydroxyapatite grafting material: histologic evaluation. Int J Periodontics Restorative Dent 2002; 22(6): 575-81.

[24] Ikoma T, Yamazaki A, Nakamura S, et al. Preparation and dielectric property of sintered monoclinic hydroxyapatite. J Mater Sci Lett 1999; 18: 1225-8.

[25] Kawano S, Morotomi T, Toyono T, et al. Establishment of dental epithelial cell line (HAT-7) and the cell differentiation dependent on Notch signaling pathway. Connect Tissue Res 2002; 43: 409-12.

[26] Xu L, Takahashi R, Harada H, et al. Effect of BMP-2 on gene expression of enamel matrix proteins at the dental epithelial cell line. Open Biotechnol J 2007; 1: 18-20.

[27] Hanagata N, Takemura T, Monkawa A, et al. Phenotype and gene expression pattern of osteoblast-like cells cultured on polystyrene and hydroxyapatite with pre-adsorbed type-1 collagen. J Biomed Mater Res A 2007; 83(2): 362-71.

[28] Takemura T, Fan HS, Ikoma T, et al. Gene expression profile of osteoblast-like cells on calcium phosphate biomaterials. Key Eng Mater 2007; 330-332: 1087-1090.

[29] Yan Q, Zhang Y, Li W, et al. Differentiation of human ameloblastlineage cells in vitro. Eur J Oral Sci 2006; 114: 154-8. 
[30] DenBesten PK, Machule D, Zhang Y, et al. Characterization of human primary enamel organ epithelial cells in vitro. Arch Oral Biol 2005; 50(8): 689-94.

[31] Moran RA, Brown EM, Bawden JW. Immunohistochemical local-

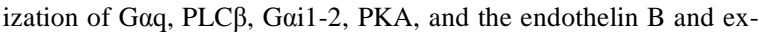
tracellular $\mathrm{Ca}^{2+}$-sensing receptors during early amelogenesis. J Dent Res 2000; 79(11): 1896-1901.

Received: December 17, 2007
Accepted: December 17, 2007
[32]

Mathias RS, Mathews $\mathrm{CH}$, Machule $\mathrm{C}$, et al. Identification of the calcium-sensing receptor in the developing tooth organ. J Bone Miner Res 2001; 16(12): 2238-44.

[33] Coin R, Haikel Y, Ruch JV. Effects of apatite, transforming growth factor beta-1, bone morphogenetic protein-2 and interleukin-7 on ameloblast differentiation in vitro. Eur J Oral Sci 1999; 107: 48795 